Rournson, G. N. (1954). J. gen. Microbiology. 11, 412-419.

\title{
The Effect of certain Enzyme Inhibitors on Respiration and on Penicillin Formation by Penicillium chrysogenum
}

\author{
By G. N. ROLINSON \\ Research Department, Bacteriology Division, Boots Pure Drug Co. Ltd., Nottingham
}

SUMMARY: The effect of phenol, mercuric chloride, fluoride, bisulphite, azide, malonate, $2: 4$-dinitrophenol and cyanide on respiration and penicillin production was studied using suspensions of washed penicillin-producing mycelium of Penicillium chrysogenum in Warburg flasks. Inhibition of penicillin production by phenol and by mercuric chloride closely followed the inhibition of respiration. Both fluoride and bisulphite inhibited penicillin production to a greater extent than respiration. Malonate was without effect on respiration or penicillin production, possibly because the $\mathrm{pH}$ was too high to allow a sufficient concentration of undissociated acid. Penicillin production was inhibited by 2:4-dinitrophenol at concentrations which had little effect on respiration, suggesting that phosphate bond energy is utilized in penicillin formation. Penicillin production was extremely sensitive to cyanide. A concentration of $0.000002 \mathrm{M}-\mathrm{KCN}$, which caused no significant inhibition of respiration, depressed the rate of penicillin production to $c .25 \%$ of normal. Maximum rates of penicillin production and respiration are dependent on cyanide-sensitive systems but an alternative, relatively cyanide-stable system allows both respiration and penicillin production to proceed at $c .25 \%$ of the maximum rate.

Despite a continuing increase in knowledge of the fermentation conditions necessary to obtain high penicillin yields, virtually nothing is known of the mechanism, or path, of synthesis of penicillin. It is well known that the side chain of the penicillin molecule can be supplied in the form of a precursor such as phenylacetic acid, the benzyl group of which is incorporated into the molecule of penicillin G; but no successful attempts to supply precursors for other parts of the molecule have been reported. Sulphur is a constituent of the molecule and organic sulphur-containing compounds such as L-cystine, L-cysteine, methionine and glutathione appear to be utilized by the mould in preference to sulphate for penicillin formation (Stevens, Vohra, Inamine \& Roholt, 1953). So far as I am aware, no intermediate compounds in the pathway of penicillin synthesis have been identified and nothing is known of the enzymes involved. Experiments were therefore carried out with certain enzyme inhibitors in an attempt to throw some light on the mechanism of penicillin formation.

\section{METHODS}

The experiments were carried out with washed penicillin-producing mycelium suspended in a medium of known composition in Warburg flasks. The penicillin produced after $1 \frac{1}{2}-2 \mathrm{hr}$. was then assayed by the biological cup-plate method in the usual way. This technique enabled penicillin production to be studied as a reaction under conditions which changed very little during an experiment and which could be controlled in a way impossible in a complete fermentation. 
The samples of mycelium used were obtained from highly aerated submerged fermentations during the period of active penicillin production. Mycelium was washed by repeated filtration on a Buchner funnel to remove penicillin and original medium, and was finally suspended in the medium to be used in the experiment. It was necessary to repeat the washing at least 3 times to ensure that the penicillin concentration in the suspension was $<2 \mathrm{units} / \mathrm{ml}$.

The washing of the mycelium, which might take up to $30 \mathrm{~min}$., did not impair its penicillin-producing ability. With adequate agitation, washed mycelium suspended in a medium similar to that used in the fermentation from which it was obtained, formed penicillin at a rate at least equal to that in the unaltered fermentation itself. Two ml. volumes of suspension were used in each Warburg flask, maintained at $26^{\circ}$.

For maximum rates of penicillin production it was essential that the rate of oxygen uptake by the mycelium should not be limited by the rate of solution of oxygen in the Warburg flasks. Agitation of the flasks at 200 strokes/min. with a $5 \mathrm{~cm}$. stroke was required to provide an adequate rate of solution for a suspension of mycelium of density equivalent to $0.7 \mathrm{~g}$. dry-wt. mycelium/ $100 \mathrm{ml} .(0.7 \%)$. With the Warburg apparatus used, adequate aeration could not be provided for suspensions of density $1.0 \%$ or greater. The oxygen demand of the mycelium, and hence the degree of agitation required, varies with the age of the mycelium, the conditions under which it is grown, and the composition of the medium used for suspending. In all these experiments the mycelium used was of a standard age having been grown under standard fermentation conditions in a lactose + corn steep liquor + salts medium. The organism used was a mutant which did not form pigment, derived from Penicillium chrysogenum strain W 48-701. The medium used to wash and suspend the mycelium contained: corn steep liquor, $2 \%(\mathrm{v} / \mathrm{v})$; lactose, $3 \%(\mathrm{w} / \mathrm{v}) ; \mathrm{NaNO}_{3}, \mathbf{0} \cdot 3 \% ; \mathrm{KH}_{2} \mathrm{PO}_{4}, 0.05 \% ; \mathrm{Na}_{2} \mathrm{SO}_{4}, 0 \cdot 1 \%$; phenylacetic acid, $0.02 \%$;H value $6 \cdot 0-6 \cdot 2$. It was boiled for 1-2 min. to destroy any penicillinase in the corn steep liquor and then filtered. With this medium, penicillin production occurred at a uniform rate in Warburg flasks during at least $3 \mathrm{hr}$. That aeration was adequate was confirmed in every experiment either by rocking the manometers at a lower rate for a short period of time to demonstrate that the rate of oxygen uptake was not limiting, or by carrying out the whole experiment in duplicate with two suspensions of different mycelial densities.

Despite the relatively brief duration of the experiments, some growth (usually $c .10 \%$ ) did occur, with a corresponding increase in the rate of oxygen uptake. At the end of the experiment the contents of the flasks were washed out with $0.05 \mathrm{M}-\mathrm{KH}_{2} \mathrm{PO}_{4}+\mathrm{NaOH}$ buffer $(\mathrm{pH} \mathrm{7.0)}$ ) and made up to standard volume before assay. Rupture of the cell walls of washed mycelium by shaking with glass beads in a Mickle disintegrator and assay of the penicillin liberated showed that the penicillin within the mycelium at the beginning of an experiment could contribute $<2$ units/ml. to a normal suspension by outward diffusion during the experiment.

The presence of enzyme inhibitors did not interfere with the assay of the penicillin content of the suspensions. The original $2 \mathrm{ml}$. of suspension in the 
Warburg flasks could usually be diluted at least 3 times before assay so that at the maximum concentration of each inhibitor used, none showed any inhibition on the assay plates when tested separately nor did they alter the inhibition zone diameters of standard penicillin solutions.

In the experiments with cyanide, suitable mixtures of $\mathrm{KCN}$ and $\mathrm{KOH}$ were used (Umbreit, Burris \& Stauffer, 1945) in the centre well of the Warburg flasks to prevent cyanide distilling over from the suspension into the $\mathrm{KOH}$ in the centre well and so altering the concentration of cyanide during the experiment.

\section{RESULTS}

Figures for oxygen uptake and penicillin production are given as percentages of those obtained in controls without inhibitor.

\section{Effects of phenol and mercuric chloride}

Phenol and mercuric chloride were chosen to determine the effect of relatively non-specific poisons; the results are shown in Fig. 1. In low concentrations, phenol appeared to stimulate oxygen uptake slightly without any
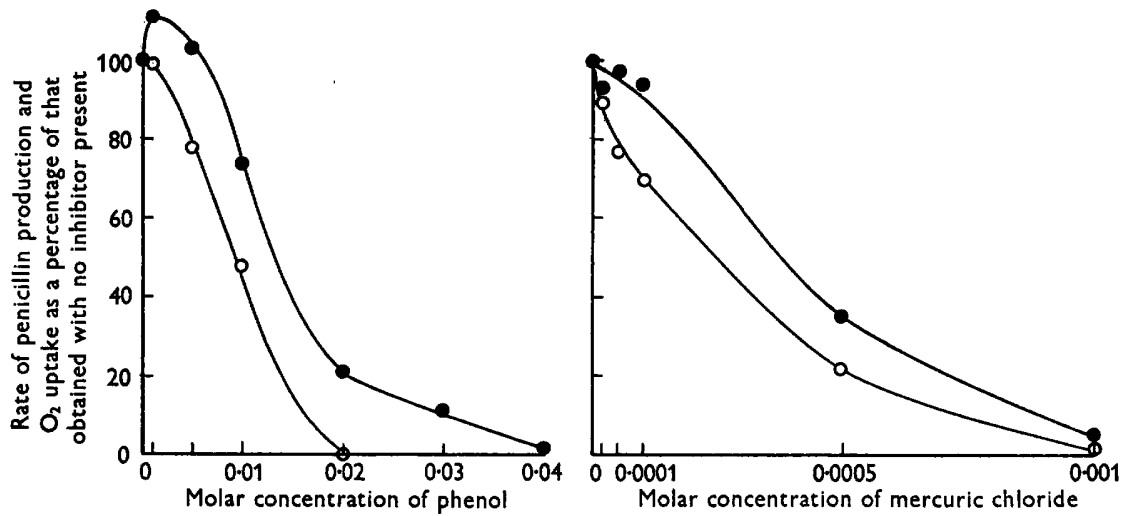

Fig. 1. Effect of phenol and mercuric chloride on penicillin production $(O-O)$ and oxygen uptake ) by $\boldsymbol{P}$. chrysogenum.

corresponding stimulation of penicillin production. Concentrations $>0.002 \mathrm{M}$, however, caused a similar degree of inhibition of both oxygen uptake and penicillin production so that although the curve for respiration was displaced upwards by the slight stimulatory effect of phenol it was essentially parallel to that for penicillin production. In this case the effect on penicillin production is probably indirect, as a result of the effect on the mycelium as a whole. The effect of mercuric chloride on penicillin production is also paralleled by its effect on total oxygen uptake.

\section{Fluoride and bisulphite}

As shown in Table 1, both fluoride and bisulphite inhibited penicillin production to a greater extent than total oxygen uptake. Sodium fluoride at $0.02 \mathrm{~m}$ had little effect on respiration but penicillin production was $c .50 \%$ of 
maximum; with $0.08 \mathrm{~m}$ respiration was markedly depressed, and no penicillin was detected. With bisulphite, a concentration of $0.01 \mathrm{~m}$ depressed oxygen uptake to $69 \%$ of maximum and penicillin production to $24 \%$ of maximum.

Table 1. Effect of sodium fuoride and sodium bisulphite on penicillin production and oxygen uptake by Penicillium chrysogenum

Rates of penicillin production and oxygen uptake as percentage of that obtained without inhibitor. Concentrations of sodium bisulphite up to $0 \cdot 02 \mathrm{~m}$ showed no significant oxygen uptake during the period of taking manometer readings as a result of oxidation to sulphate.

\begin{tabular}{|c|c|c|c|c|c|}
\hline \multicolumn{3}{|c|}{ Sodium fluoride } & \multicolumn{3}{|c|}{ Sodium bisulphite } \\
\hline $\begin{array}{c}\text { Conc. } \\
\text { (M) }\end{array}$ & $\begin{array}{c}\text { Rate of } \mathbf{O}_{2} \\
\text { uptake } \\
(\%)\end{array}$ & $\begin{array}{c}\text { Rate of } \\
\text { penicillin } \\
\text { production } \\
(\%)\end{array}$ & $\begin{array}{c}\text { Conc. } \\
\text { (M) }\end{array}$ & $\begin{array}{c}\text { Rate of } \mathrm{O}_{2} \\
\text { uptake } \\
(\%)\end{array}$ & $\begin{array}{c}\text { Rate of } \\
\text { penicillin } \\
\text { production } \\
(\%)\end{array}$ \\
\hline $\mathbf{0}$ & 100 & 100 & 0 & 100 & 100 \\
\hline 0.01 & 100 & 92 & $0 \cdot 01$ & 69 & 24 \\
\hline 0.02 & 91 & 54 & $0 \cdot 02$ & $17 \cdot 9$ & 0 \\
\hline $0 \cdot 04$ & $62 \cdot 5$ & 33 & - & - & - \\
\hline 0.08 & 42 & 0 & - & - & - \\
\hline
\end{tabular}

\section{Malonate}

Concentrations of sodium malonate up to $0 \cdot 2 \mathrm{M}$ had no effect on respiration or on penicillin production; higher concentrations interfered with the assay of penicillin. The absence of inhibition of respiration by malonate is probably because the $\mathrm{pH}$ value at which these experiments were carried out was too high to allow a sufficient concentration of undissociated acid. Turner \& Hanly (1947) reported that $0.05 \mathrm{M}$-malonate inhibited oxygen uptake by carrot root slices at $\mathrm{pH} \mathrm{5.0}$ and less, but stimulated respiration at $\mathrm{pH} \mathrm{6.0}$ and greater. Experiments with Penicillium chrysogenum were not carried out at $\mathrm{pH}$ values lower than 6.0 because of the rapid fall in the rate of penicillin production as the $\mathrm{pH}$ was lowered.

\section{Azide}

Sodium azide did not inhibit penicillin production to any markedly greater extent than total respiration; results of a typical experiment are shown in Table 2. With 0.0001 and $0.0002 \mathrm{M}$-azide, the figures for penicillin production are somewhat lower than for oxygen uptake but the effect is not marked and

Table 2. Effect of sodium azide on penicillin production and oxygen uptake by Penicillium chrysogenum.

Rates of penicillin production and oxygen uptake as percentage of that obtained without azide.

$\begin{array}{ccc}\text { Sodium azide } & \begin{array}{c}\text { Rate of } \mathrm{O}_{2} \\ \text { uptake } \\ (\mathrm{M})\end{array} & \begin{array}{c}\text { Rate of penicillin } \\ \text { production } \\ (\%)\end{array} \\ 0 & 100 & 1 \%) \\ 0.0001 & 92 & 77 \cdot 5 \\ 0.0002 & 57 & 36 \\ 0.0005 & 20 & 20 \\ 0.001 & 15 & 8 \cdot 1\end{array}$


hardly comparable with the effect of fluoride or bisulphite. However, azide is known to be a powerful inhibitor of respiration, and any specific effect on penicillin production might well be masked.

\section{2:4-Dinitrophenol}

Penicillin production was very much more sensitive to 2:4-dinitrophenol than was respiration (Fig. 2). A concentration of $0.0004 \mathrm{M}$ caused almost no inhibition of respiration but penicillin production was depressed to $c .50 \%$ of maximum. With $0.0006 \mathrm{M}$, penicillin production was almost completely inhibited yet respiration was still $c .60 \%$ of maximum.

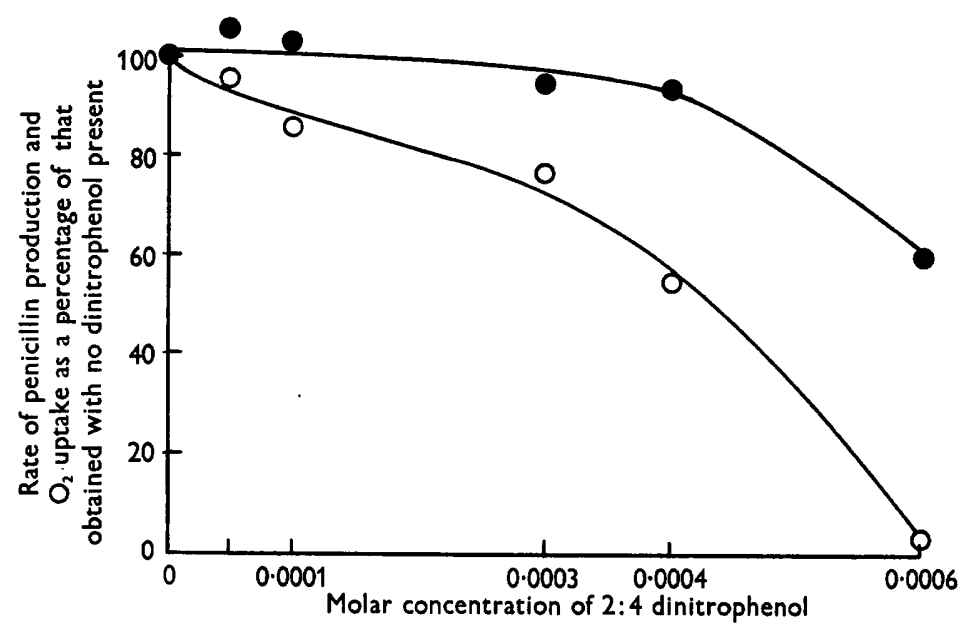

Fig. 2. Effect of 2:4-dinitrophenol on penicillin production $(\mathrm{O}-\mathrm{O}$ ) and oxygen uptake ( - - b) by $P$. chrysogenurn.

\section{Cyanide}

Penicillin production was extremely sensitive to cyanide (Figs. 3 and 4); $0.000002 \mathrm{M}-\mathrm{KCN}$, which had no significant effect on oxygen uptake, inhibited penicillin production to $c .25 \%$ of the maximum. A 50-fold increase in cyanide concentration (i.e. to $0.0001 \mathrm{~m}$ ) was required to bring about a similar degree of inhibition of respiration. Penicillin production and respiration both appeared to contain some proportion or component which was relatively cyanide stable (Fig. 3). A concentration of $0.001 \mathrm{M}-\mathrm{KCN}$ had little greater effect on penicillin production than did $0.000002 \mathrm{M}$, the latter being sufficient to depress penicillin production to $c .25 \%$ of maximum, and a concentration of $0.005 \mathrm{M}-\mathrm{KCN}$ (i.e. an increase of over 2000 -fold) was required to inhibit penicillin production completely. Similarly, although a concentration of 0.0001 м-KCN inhibited respiration to $c .25 \%$ of maximum a concentration of $0.005 \mathrm{M}-\mathrm{KCN}$ (a 50 -fold increase) was required to inhibit respiration completely. The results in Fig. 3 also show that when poisoned with cyanide (e.g. with $0.0001 \mathrm{M}-\mathrm{KCN}$ ) the cyanide-stable proportion allows both penicillin production and respiration to proceed at the same reduced rate, i.e. c. $25 \%$ of maximum. 


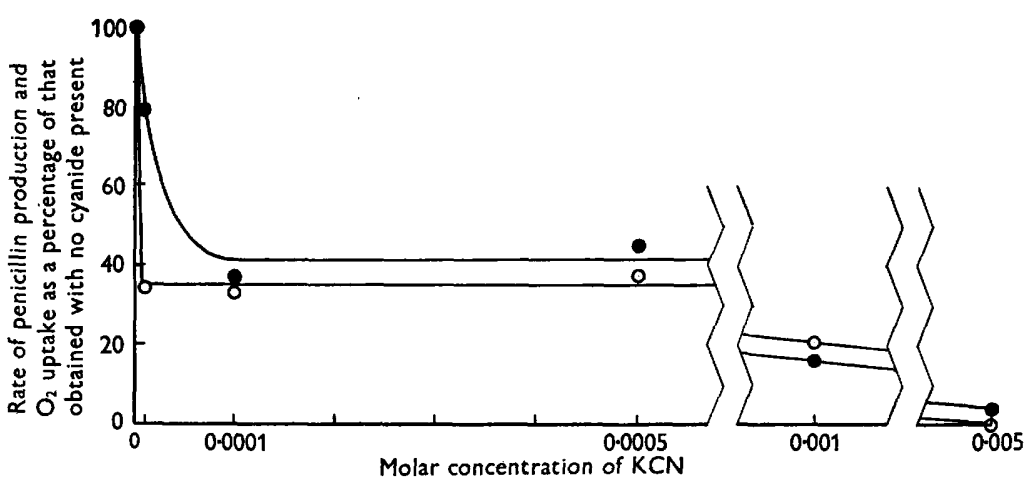

Fig. 3. Effect of cyanide on penicillin production $(\mathrm{O}-\mathrm{O})$ and oxygen uptake ( -0 ) by $P$. chrysogenum.

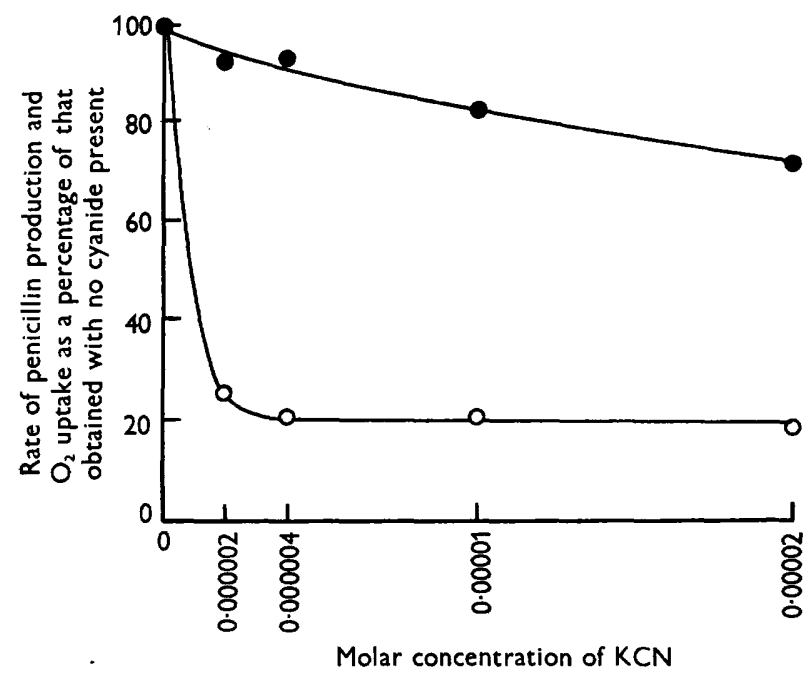

Fig. 4. Effect of relatively low concentrations of cyanide on penicillin production $(\mathrm{O}-\mathrm{O})$ and oxygen uptake (- - ) by $P$. chrysogenum.

\section{DISCUSSION}

The results with phenol and mercuric chloride show that penicillin production is not always depressed preferentially, compared with some other cell process such as respiration, regardless of the inhibiting agent. The results with phenol were somewhat complicated by the slight stimulation of respiration at low concentrations, an effect similar to that reported by Hugo \& Street (1952) with Escherichia coli.

The results with fluoride and bisulphite suggest that these substances interfere either directly with the mechanism of penicillin production or by preventing some other processes which furnish intermediates in the formation of penicillin. The results with 2:4-dinitrophenol were essentially similar to those obtained in experiments on other synthetic processes such as the synthesis of proteins and enzymes (Clifton, 1946; Hotchkiss, 1947; Frantz, 
Zamecnik, Reese \& Stephenson, 1948; Fowler, 1951); concentrations which had little effect on total oxygen uptake markedly inhibited penicillin synthesis. This suggests that phosphate bond energy is utilized in the synthesis of penicillin, as in the other synthetic processes previously mentioned, since 2:4-dinitrophenol is known to uncouple respiration from phosphorylation (Loomis \& Lipmann, 1948).

The results with cyanide show that a cyanide-sensitive system is involved for maximum oxygen uptake and penicillin production but that an alternative, and relatively cyanide-insensitive, system allows oxygen uptake and penicillin production to proceed at c. $25 \%$ of the maximum rate. The inhibition of penicillin production by cyanide would appear to be a direct effect because penicillin production and respiration were not equally sensitive to cyanide. A concentration of $0.000002 \mathrm{M}-\mathrm{KCN}$ decreased penicillin production to only c. $25 \%$ of the maximum rate, i.e. the cyanide-sensitive system was completely blocked yet the rate of oxygen uptake was not significantly affected. A concentration of $0.0001 \mathrm{M}$ was required to decrease the respiration to $c .25 \%$ of maximum. This does not, however, rule out the possibility that the cyanidesensitive systems in penicillin production and respiration are the same, since those enzyme molecules concerned with penicillin synthesis might conceivably be more accessible or sensitive to cyanide. In either case, the results indicate that a cyanide-sensitive enzyme is involved in the biosynthesis of the penicillin molecule.

There is no evidence as to the nature of such an enzyme. Inhibition with cyanide suggests an iron- or copper-containing enzyme. It may be significant that iron is essential for penicillin production as distinct from growth (Jarvis \& Johnson, 1950); approximately 20 times as much iron being required for maximum penicillin production as for maximum growth only.

Despite the differences in the relative sensitivity to cyanide, the effects on respiration and penicillin production have something in common. When the respective cyanide-sensitive systems are completely blocked (i.e. with $0.0001 \mathrm{M}-\mathrm{KCN}$ ) both respiration and penicillin production proceed at the same reduced rate of $c .25 \%$ of maximum. This suggests that the cyanide-stable mechanism may be common to both penicillin production and respiration, i.e. be concerned with hydrogen transfer in both processes. As a working hypothesis, therefore, it is suggested that one step in the biosynthesis of penicillin involves an oxidation and that a cyanide-sensitive enzyme is essential in order that this step should proceed at the maximum rate. Further, a cyanide-sensitive system seems to be essential for the maximum rate of respiration and this may or may not be identical with that involved in penicillin production. It is further suggested that an alternative enzyme system, relatively insensitive to cyanide, is present which allows hydrogen transfer to proceed at a limited rate, so that both respiration and penicillin production proceed at c. $25 \%$ of the maximum rate. The oxygen uptake involved in such an oxidative step in penicillin synthesis might account for only a very small proportion of the total oxygen uptake and might not be noticed when penicillin synthesis was blocked by low concentrations of cyanide which had little effect on the total oxygen uptake. 
The author is indebted to Mr C. E. Coulthard and to Dr M. Lumb for their interest in the work, to Mr P. F. Washbrook for technical assistance, and to the Standards Department of Boots Pure Drug Co., Ltd. for the penicillin assays.

\section{REFERENCES}

Clifton, C. E. (1946). Microbial assimilations. Advanc. Enzymol. 6, 269.

Fowler, C. B. (1951). The relationship between fermentation and enzymatic adaptation. Biochim. Biophys. Acta, 7, 563.

Frantz, I. D., Zamecnik, P. C., Reese, J. W. \& Stephenson, M. L. (1948). The effect of dinitrophenol on the incorporation of alanine labelled with radioactive carbon into the proteins of slices of normal and malignant rat liver. J. biol. Chem. 174, 773.

Hoтchkiss, R. D. (1947). The assimilation of amino acids by respiring washed staphylococci. Fed. Proc. 6, 263.

Hugo, W. B. \& Streer, H. E. (1952). The effect of phenol, 2-phenoxyethanol and cetyltrimethylammonium bromide on the oxidation of various substrates by Escherichia coli. J. gen. Microbiol. 6, 90.

Jarvis, F. G. \& Johnson, M. J. (1950). The mineral nutrition of Penicillium chrysogenum Q176. J. Bact. 59, 51.

Loomis, W. F. \& LIPMANN, F. (1948). Reversible inhibition of the coupling between phosphorylation and oxidation. J. biol. Chem. 173, 807.

Stevens, C. M., Vohra, P., Inamine, E. \& Roholt, O. A. (1953). Utilisation of sulphur compounds for the biosynthesis of penicillins. J. biol. Chem. 205, 1001.

TURNer, J. S. \& Hanly, V. (1947). Malonate and plant respiration. Nature, Lond. $160,296$.

Umbreit, W. W., Burris, R. H. \& Stauffer, J. F. (1945). Manometric Techniques and Related Methods for the Study of Tissue Metabolism. Minneapolis, Minn. U.S.A.: Burgess Publishing Co.

(Received 26 May 1954) 